\title{
Accuracy of MRI skeletal age estimation for subjects 12-19. Potential use for subjects of unknown age
}

\section{Serenella Serinelli, Valeria Panebianco,}

Milvia Martino, Sofia Battisti, Karina Rodacki, Enrico Marinelli, Fulvio

\section{Zaccagna, et al.}

International Journal of Legal Medicine

ISSN 0937-9827

Int J Legal Med

DOI 10.1007/s00414-015-1161-y

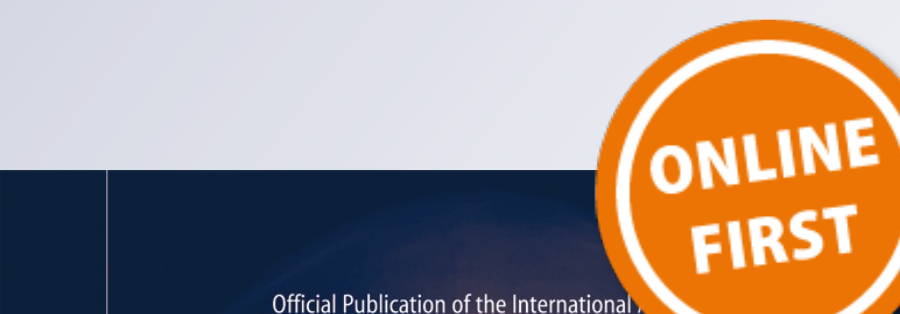

Official Publication of the Internationa

International Journal of Legal Medicine 
Your article is protected by copyright and all rights are held exclusively by SpringerVerlag Berlin Heidelberg. This e-offprint is for personal use only and shall not be selfarchived in electronic repositories. If you wish to self-archive your article, please use the accepted manuscript version for posting on your own website. You may further deposit the accepted manuscript version in any repository, provided it is only made publicly available 12 months after official publication or later and provided acknowledgement is given to the original source of publication and a link is inserted to the published article on Springer's website. The link must be accompanied by the following text: "The final publication is available at link.springer.com". 


\title{
Accuracy of MRI skeletal age estimation for subjects 12-19. Potential use for subjects of unknown age
}

\author{
Serenella Serinelli • Valeria Panebianco • Milvia Martino • Sofia Battisti • \\ Karina Rodacki • Enrico Marinelli • Fulvio Zaccagna • Richard C. Semelka • Ernesto Tomei
}

Received: 17 December 2013 / Accepted: 12 February 2015

(C) Springer-Verlag Berlin Heidelberg 2015

\begin{abstract}
Introduction In forensic practice, there is a growing need for accurate methods of age estimation, especially in the cases of young individuals of unknown age. Age can be estimated through somatic features that are universally considered associated with chronological age. Unfortunately, these features do not always coincide with the real chronological age: for these reasons that age determination is often very difficult. Our aim is to evaluate accuracy of skeletal age estimation using Tomei's MRI method in subjects between 12 and 19 years old for forensic purposes.

Material and methods Two investigators analyzed MRI images of the left hand and wrist of 77 male and 74 female caucasian subjects, without chronic diseases or developmental
\end{abstract}

S. Serinelli $(\bowtie) \cdot$ E. Marinelli

Department of Anatomy, Histology, Forensic Medicine and Orthopedics, "Sapienza-University of Rome",

Viale Regina Elena 336, 00161 Rome, Italy

e-mail: s.serinelli@gmail.com

V. Panebianco $\cdot$ M. Martino $\cdot$ F. Zaccagna $\cdot$ E. Tomei Department of Radiological Sciences, Oncology and Pathology, "Sapienza-University of Rome", Viale Regina Elena, 324, 00161 Rome, Italy

S. Battisti • R. C. Semelka

Department of Radiology, University of North Carolina, 101

Manning Drive, Chapel Hill, NC 27514, USA

S. Battisti

Department of Radiology, Campus Biomedico of Rome, Via Álvaro del Portillo 21, 00128 Rome, Italy

K. Rodacki

Ecomax - Centro de Diagnóstico por Imagem, RuaTiradentes, no 303 BomRetiro, CEP 89010-630 Blumenau, SC, Brazil disorders, whose age ranged from 12 to 19 years. Skeletal maturation was determined by two operators, who analyzed all MRI images separately, in blinded fashion to the chronological age. Inter-rater agreement was measured with Pearson $\left(R^{2}\right)$ coefficient. One of the examiners repeated the evaluation after 6 months, and intraobserver variation was analyzed. Bland-Altman plots were used to determine mean differences between skeletal and chronological age.

Results Inter-rater agreement Pearson coefficient showed a good linear correlation, respectively, 0.98 and 0.97 in males and females. Bland-Altman analysis demonstrated that the differences between chronological and skeletal age are not significant. Spearman's correlation coefficient showed good correlation between skeletal and chronological age both in females $\left(R^{2}=0.96\right)$ and in males $\left(R^{2}=0.94\right)$.

Conclusions Our results show that MRI skeletal age is a reproducible method and has good correlation with chronological age.

Keywords Forensic $\cdot$ Age estimation · MRI · Children · Hand-wrist

\section{Introduction}

In forensic practice, there is a growing need for accurate methods of age estimation, especially in the cases of young individuals with no valid proof of their date of birth [1]. According to the latest UNICEF estimations, about 51 million births go unregistered in developing countries each year [2]. As a result of these circumstances, age determination of living individuals has become an essential part of forensic practice [3]. For example, it is crucial to determine the exact age of a young individual in order to obtain a correct management of refugees, asylum seekers, human trafficking victims, and adopted children [4]. Furthermore, in forensic practice, when 
a person is accused of a crime, the knowledge of his/her age will determine if the individual should be considered criminally responsible, and if he/she will be judged by adult or juvenile criminal justice systems [5].

In every case, it is important to ensure that local authorities safeguard vulnerable groups, such as individuals less than 18 years of age or other thresholds [6]. For example, according to the Committee on Migration, Refugees and Population [7], protecting the so-called "separated children" is a fundamental issue. Separated children are defined as individuals under 18 years of age, outside their country of origin and separated from both parents, or their previous legal, or customary primary caregiver [8]. A person aged 18 is legally considered an adult, who can be incarcerated in a detention center, and is at risk of being removed from the country. Despite this institution, detention of separated children is still common in several countries, and they are often detained together with adults. Additionally, there is a high number of age disagreement cases, between asylum seekers who claim to be under 18 and immigration officials who suppose they are older.

Moreover, age has a fundamental importance in the field of criminal law, as it can determine whether a young person has any criminal responsibility, and may have an influence on how and where the young person is sentenced. A field of application of age determination is the circumstance of young offenders who claim to be younger than their true age, in order not to be considered criminally responsible, or to be judged by the juvenile justice system, to benefit from less severe sentences [9]. For example, in Italy, there are two important criminal age thresholds: 14 and 18 years. Fourteen years old is the minimum age of criminal responsibility. Between 14 and 18 years, it must be ascertained, for each case, if the offender has an adequate level of maturity and psychological development to be considered criminally responsible. If the offender has reached the age of 18 , it is presumed that he/she is able of understanding and taking act and is therefore criminally liable. In addition, the threshold of 16 years old is important for certain procedural situations: the period of detention and some features of the proceedings.

In all the aforementioned cases, it is really important to know the age of the young person. Age can be estimated by measuring or observing features such as somatic, psychological, dental, or skeletal indicators which are universally considered associated with chronological age. Unfortunately, these features do not always match with each other, and they do not always coincide with the real chronological age, for these reasons that age determination is often very difficult. There are many variables that may result in discrepancies between biological development and chronological age; for example, some reports describe significant differences between estimated and chronological age among different ethnic groups [10-13]. Furthermore, low socioeconomic status, some diseases, malnutrition, and poor hygiene significantly affect development, causing a slower rate of maturation, which results in an underestimation of age $[14,15]$. Such underestimation does not disadvantage the examined person. On the other hand, an overestimation of age, due to conditions that accelerate development (precocious puberty, adreno-genital syndrome, and hyperthyroidism), must be avoided as it causes a disadvantage in legal terms [16].

According to the Study Group on Forensic Age Diagnostics of the German Society of Legal Medicine [17], although a wide range of diagnostic procedures for age estimation is available, only few of these appear to be suitable for forensic application in living individuals, taking into account ethical and medicolegal aspects. The most suitable methods currently available are as follows: physical examination with determination of anthropometric measures and inspection of signs of sexual maturation; X-ray examination of the left hand; dental examination with determination of the dental status and X-ray examination of the dentition; if the skeletal development of the hand is completed, an additional examination of the clavicles should be carried out. These methods should be used together to obtain a significant increase of the diagnostic accuracy and to reduce the danger of under/ overestimation of chronological age. Recently, combined methods have been used with appreciable results [18].

Regarding skeletal age determination, many anatomical districts have been investigated through radiological approaches: left hand-wrist [19, 20], clavicle [21, 22], pelvis [23], knee [24, 25]. Among these, the most commonly performed technique is the X-ray of the left hand-wrist using Greulich and Pyle (GP) and Tanner and Whitehouse (TW) methods. Although these methods are routinely used and often considered an effective instrument of forensic age estimation practice [26-29], some medical specialists contest their accuracy for age assessment for forensic purposes [11, 30, 31]. Age estimation with these techniques has a described margin of error of 2-3 years, which is too inaccurate to confirm if an individual is over or under 14 or 18 years, which are ages of judicial importance in many countries. Additionally, these methods expose the young individuals to radiations. For this reason, some authors tried to use safer radiological methods of analysis, such as ultrasounds [32-34].

Our purpose is to evaluate a skeletal age estimation with a noninvasive technique such MRI to determine its correlation with chronological age between 12 and 19 years old.

\section{Material and methods}

\section{Subjects and materials}

This perspective study analyzed MRI images of the left hand and wrist taken from 77 male to 74 female subjects, who ranged in age from 12 to 19 years. The chronological age 
was assessed by identity proof given with birth registration of each participants. Approval for this perspective study was granted by the Institutional Ethics Committee, and informed consent was obtained from all parents/guardians. All subjects included in our study were Italian-Caucasian without history of chronic diseases or developmental disorders. All the images were acquired between 2010 and 2011 with an open low-field clinical Magnet (0.2T) (G-Scan, Esaote, Genoa, Italy) with the hand positioned in a small coil, to limit movement. A comfortable environment was also created, all for the children. All images were obtained in the coronal plane using a standard spin-echo imaging T1-3D sequence with the following parameters: field of view $(\mathrm{FoV}) 140 \times 120 \times 40 \mathrm{~mm}$; slice thickness $=$ $1.3 \mathrm{~mm}$; acquisition matrix $=192 \times 110 \times 24$; time echo time/ repetition time $(\mathrm{TE} / \mathrm{TR})=16 / 38 \mathrm{~ms}$; flip angle $=65^{\circ}$.

Skeletal age was determined by two investigators, (A) and (B), respectively, who analyzed all MRI images separately. The two observers were blinded to the chronological age of the subjects, and only subject's gender was known. All assessments were performed in accordance with a recent skeletal MRI atlas method using sex and age-matched MRI, the Tomei et al. method [35].

It is a grade system based on the analysis of tubular and carpal bones of the left wrist/hand in different stages of chronological maturation, from the first phase of cartilaginous mass appearance to the final fusion of bony metaphysis and epiphysis, to assess skeletal age [36]. The MRI scoring system was developed from the literature about anatomic and growth information, in conjunction with the TW method and GP Atlas. It is based on the study of the progressive maturation of nine tubular and carpal bones of the hand and wrist. To each development step, it attributed a score. The score system is based on a range that includes a minimum of 1 for all the bones and a maximum that is 12 for radius and ulna, 10 for the epiphysis of the first and third proximal phalanges, 9 for epiphysis of first and third metacarpal bones, 8 for capitate and hamate, and 7 for pisiform. The maximum score derived from the sum of all bones is 85 . With MRI, it is possible to describe more morphological features of bone ossification in relation to the different steps of cartilaginous maturation. The method uses the following criteria to define the steps of tubular and carpal bone maturation.

Regarding tubular bones:

- In the early phases of skeletal maturation, a cloud-like mass of epiphyseal cartilage is recognized.

- In the next step of maturation, a mold sculpture representing the future morphology of the bone is visible.

- The following phase is characterized by the appearance of the nucleus of ossification in the center of the metaphyseal plate. The cartilage surrounding the nucleus of ossification is predominant.
- The following phases are represented by different steps of growth of the epiphyseal ossified nucleus which is concomitant, with the progressive reduction of the thick rim of cartilage surrounding the epiphysis. The close correlation of the osseous and cartilaginous growth is not visible in the X-ray images. Furthermore, the cartilage layer surrounding the nucleus of ossification and the growth plate between epiphysis and metaphysis can be distinguished.

- The peri-puberal and puberal ages are characterized by the appearance of the small hyperintense foci of cartilage in the metaphyseal end-plate which is increased in thickness.

- The progressive bone maturation is represented by the reduction of the width of the growth plate together with the disappearance of foci of cartilage. The rim of cartilage surrounding the epiphysis is now very thin.

- In the next step, epiphysis and metaphysis are very close, and the growth plate is partly replaced by a low signal intensity line representing a process of calcification which predicts the development of interosseous bone bridges.

- The last phases of maturation are represented by the disappearance of the growth plate, the increase of multiple interosseus bone bridges, and finally the complete fusion of the epiphysis with the metaphysis.

The development of carpal bones shows some different features:

- The first phases are similar to the cartilaginous maturation of the tubular bones ("cloud-like" and mold sculpture appearance).

- The following phase is represented by the vacuolization of the cartilage which is visible like a small and hypointense nucleus in the center of the cartilaginous mass.

- The nucleus of vacuolization center increases in size.

- The appearance of first nucleus of ossification; at this time, the cartilage is a thick rim around the bone.

- The increase in size of the bone is accompanied by the progressive reduction of the layer of cartilage.

- The last phase is characterized by the diseappearance of the cartilaginous rim and the presence of articular facet between carpal bones.

The sample analyzed in this paper is not part of MRI atlas population.

Statistical analysis

Inter-rater agreement was assessed with Pearson $\left(R^{2}\right)$ coefficient. One of the examiners repeated the evaluation after an interval of 6 months, and Bland-Altman plots were used to analyze intraobserver variability. To detect potentially 
advanced or delayed aging in the sample study, Bland-Altman plots were used to determine the mean differences between skeletal MRI age and chronological age in males and females separately. Statistical analysis was performed using statistical software MedCalc (Version 12.4.0 Acacialaan 22, B-8400 Ostend, Belgium). Spearman's correlation coefficient ( $r$ ) was used to analyze each carpal and tubular bone stage development with skeletal MRI age in consensus.

\section{Results}

Inter-rater agreement Pearson $\left(R^{2}\right)$ coefficient was performed, and an excellent linear correlation was found both in male and female groups, respectively, 0.98 and 0.97. Intraobserver variability for females and males is shown in Fig. 1. Statistical analysis involved a comparison of skeletal age assessed by two operators (A and B) and chronological age. Results are presented on a scatter graph plot with Bland-Altman analysis (Fig. 2), which shows that differences between the chronological age and the MRI skeletal age are clinically not significant. Means, standard deviations (SD), minima and maxima of chronological age in skeletal age cohorts 12.0 to 18.99 years for both the operators are shown in Table 1. Spearman's correlation coefficient $(r)$ showed good linear correlation between the sum of the grade of each bone and the chronological age both in females $\left(R^{2}=0.96\right)$ and in males $\left(R^{2}=0.94\right)$. We might suppose that this new method has a sufficient accuracy to be used helping the X-ray method for first, and maybe in future to replace it. Both the operators used to slightly overestimate the age of males and females (Table 2).

\section{Discussion}

X-ray analysis of the left hand and wrist has been used for decades to estimate age and maturation in children. Anyway, the "bone age" determined with X-rays has some limitation to be used for forensic purposes, such as the exposure to ionizing radiation and the lack of accuracy.

In fact, one of the main problems arises from the consideration that the exposure to ionizing radiation for forensic reasons requires a special justification for each person examined. It has been estimated that the effective dose for a hand/wrist radiograph is $0.003 \mathrm{mSv}$, and in this case, the risk for a fatal cancer is 1 in 5,460,000 [37]. Even if this exposure to radiation is considered acceptable by someone, others argue that, especially with a different intention than diagnosis or therapy, any radiation may be harmful [38]. Moreover, in the case of age determination, the lifetime risk of cancer is larger due to the younger age of the people examined. In this cases, risks of radiation exposure should be weighed against the benefits of the procedure, considering that the existing techniques are not a
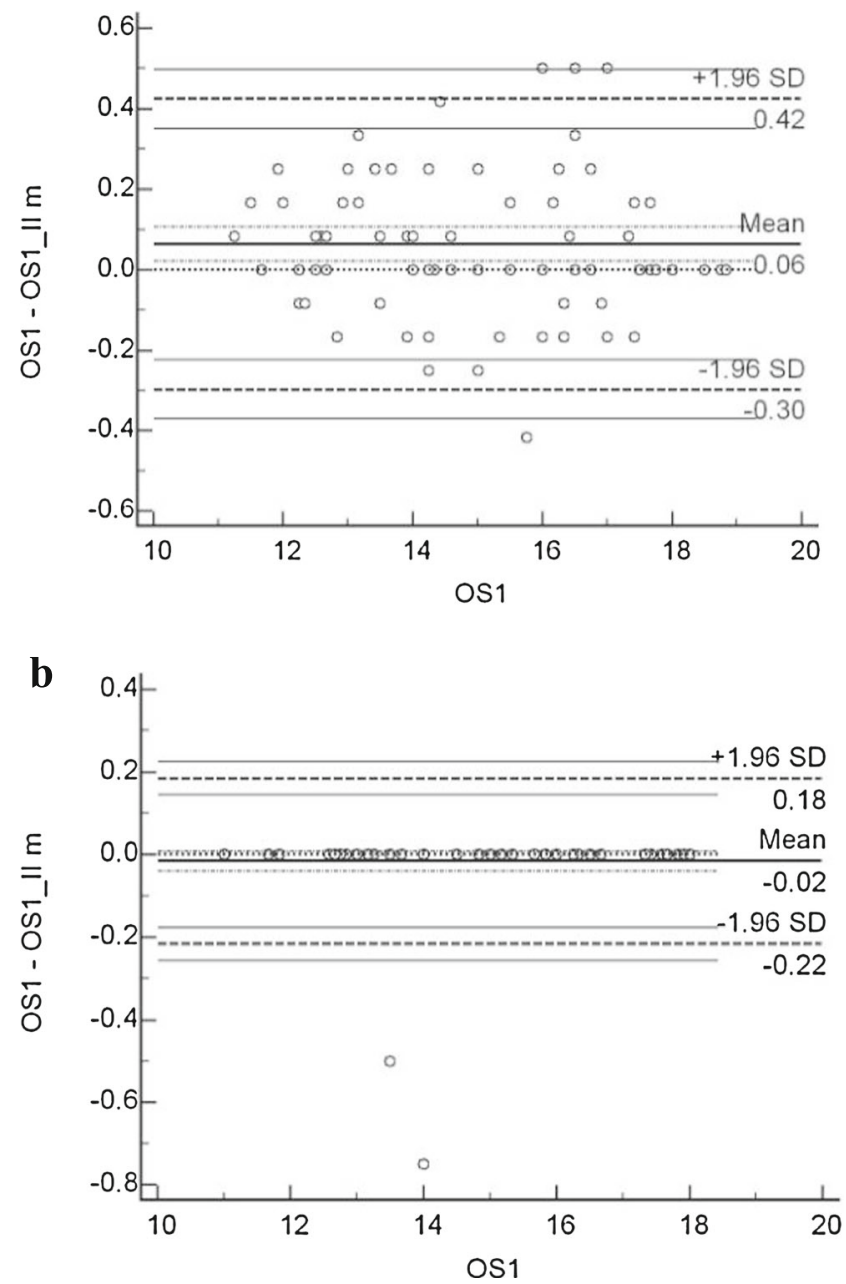

Fig. 1 Bland-Altman plots showing intraobserver variation for females (a) and males (b). OS1 is the first measure, while OS1_II $m$ indicates the second one

reliable [39]. A method of assessing age without exposure to ionizing radiation is needed. The Committee on the Rights of the Child, which monitors the implementation of Convention on the Rights of the Child, stated that "the assessment must be conducted in a safe manner, avoiding any risk of violation of the physical integrity of the child" [40]. Also, SCEP stated that "the least invasive option must always be followed and the individual's dignity must be respected at all times" [41]. According to the International Agency of Atomic Energy, "the use of ionizing radiation for human imaging for purposes other than medical diagnosis, medical treatment or biomedical research [must be] subject to the system of protection and safety" and must be carefully justified [42]. European Commission in its Basic Safety Standards of the EURATOM declared that "alternative techniques which do not involve exposure to ionizing radiation must be available" [39].

The other issue, in forensic practice, is the importance of an accurate assessment of skeletal age [43] in all age groups, due to the fact that it may determine the future of young 


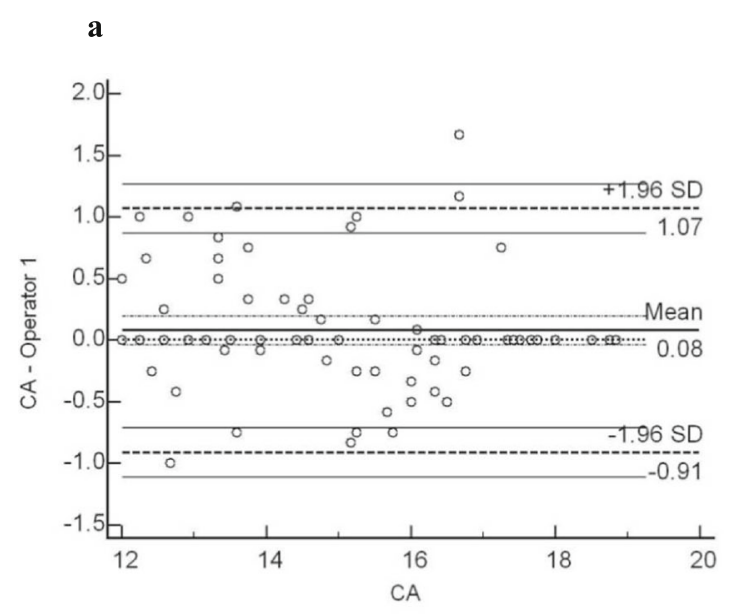

c

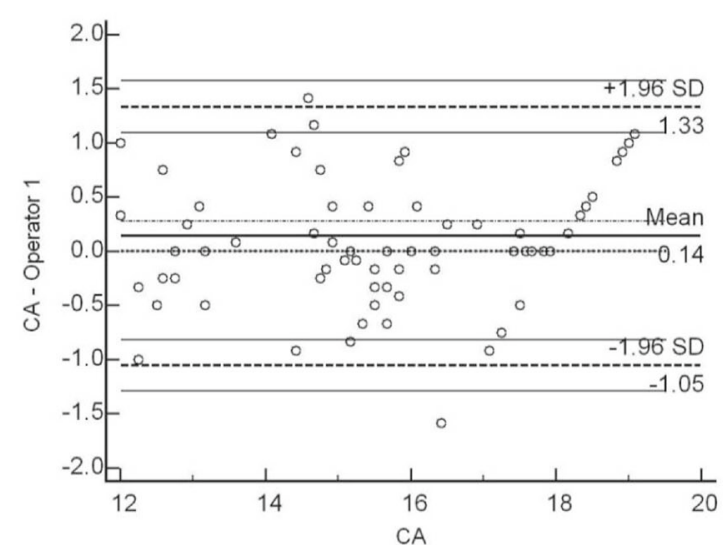

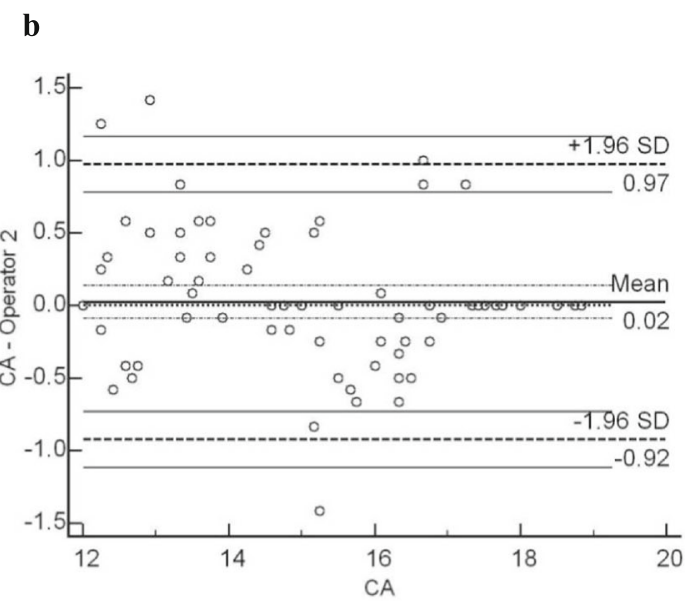

d

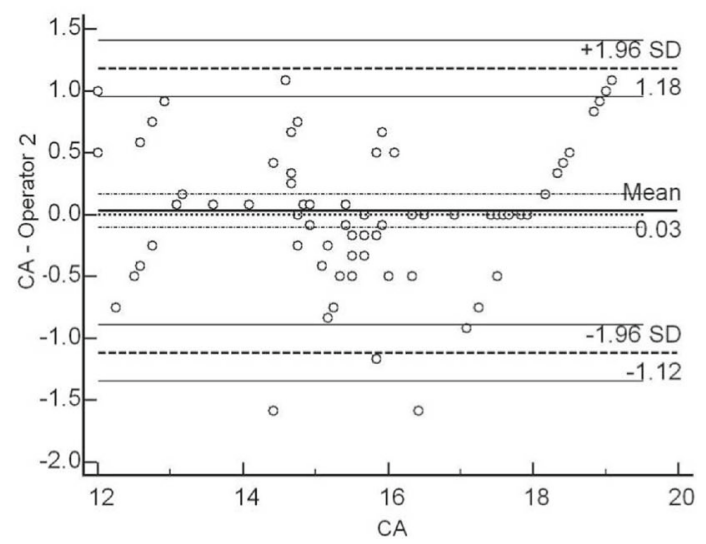

Fig. 2 Bland-Altman graph showing the differences between chronological and skeletal age for females group (a, b) and males group (c, d). At the age of 18-19 years old, almost all males show a complete maturity process: this explains the trend of linear distribution of the circles

individuals whose age is unknown. In all the aforementioned circumstances in which age assessment analysis for forensic purposes is required, the results can have very important consequences for individuals, as the aim is to determine if they should be assigned to childhood or adulthood. Inaccuracy in age estimation can negate an adult access to freedom. On the other hand, children wrongly considered older than their true age can be expected to behave in ways not appropriate to their real age [44].

For these reasons, the central aspect of an expert report is to give the most probable age of the examined individual and/or the degree of probability that the estimated age is the actual age or that it is over a particular relevant age limit [3]. As the techniques currently used are not sufficiently accurate for forensic purposes, more precise methods are needed.

Tomei et al. method [35] shows an excellent inter-rater agreement, and the differences between chronological age and MRI skeletal age are not significant. Moreover, these authors have considered some morphological features that may play a role for forensic age assessment:
1. The prepubertal transformation of the bones occurs at the metaphyseal endplate and is characterized by a stippled appearance and wavy contour, containing tiny oval hyperintense foci which may contain clumps of cartilage. These features appear in males at the age of 12 years and 6 months until the last months of 13 years old. In females, these features are seen at the prepubertal age (range 11 years and 6 months -12 years and 6 months).

2. At the age of 14 for females and at the age of 15 in males, the pisiform shows a complete ossification with the disappearance of cartilaginous rime.

3. The appearance of capping of the epiphyses of tubular bones is visible in males at 14 years old (Fig. 3a). In females at 14 years old, the growth plate is thinner; the closure of the growth plates begins at 14 years and 6 months as an hypointense line between metaphysis and epiphyses of tubular bones; the capping phenomenon is present but less pronounced than in males at this age (Fig. 3d).

4. The appearance of interosseous bone bridges is a sign of maturation that begins in males at 15 years and 10 months 
Table 1 Means, standard deviations, minima and maxima of chronological age in skeletal age cohorts 12.0 to 18.9 years

\begin{tabular}{|c|c|c|c|c|c|c|}
\hline \multirow{3}{*}{$\begin{array}{l}\text { Skeletal MRI age [in } \\
\text { years] }\end{array}$} & \multirow{2}{*}{\multicolumn{2}{|c|}{$\mathrm{n}$}} & \multicolumn{4}{|c|}{ Chronological age [in years] } \\
\hline & & & \multicolumn{2}{|l|}{ Mean \pm SD } & \multicolumn{2}{|l|}{ Min-Max } \\
\hline & Males & Females & Males & Females & Males & Females \\
\hline \multicolumn{7}{|l|}{ A } \\
\hline $11.00-11.99$ & 3 & 4 & $12.19( \pm 0.34)$ & $12.37( \pm 0.39)$ & $12-12.58$ & $12-12.92$ \\
\hline $12.00-12.99$ & 5 & 12 & $12.71( \pm 0.32)$ & $12.83( \pm 0.54)$ & $12.25-13.1$ & $12-13.58$ \\
\hline $13.00-13.99$ & 11 & 9 & $13.62( \pm 0.91)$ & $13.46( \pm 0.53)$ & $12.25-14.67$ & $13.67-14.25$ \\
\hline $14.00-14.99$ & 6 & 11 & $14.778( \pm 0.11)$ & $14.42( \pm 0.54)$ & $14.67-14.92$ & $13.58-15.25$ \\
\hline $15.00-15.99$ & 16 & 7 & $15.41( \pm 0.47)$ & $15.63( \pm 0.75)$ & $14.42-16.08$ & $14.83-16.67$ \\
\hline $16.00-16.99$ & 12 & 17 & $15.924( \pm 0.51)$ & $16.11( \pm 0.59)$ & $15.17-16.92$ & $15.17-17.25$ \\
\hline $17.00-17.99$ & 8 & 9 & $17.646( \pm 0.16)$ & $16.5( \pm 0.43)$ & $17.42-17.92$ & $16.5-17.75$ \\
\hline $18.00-18.99$ & 16 & 5 & $18.19( \pm 0.83)$ & $18.52( \pm 0.32)$ & $16.42-19.08$ & $18-18.83$ \\
\hline \multicolumn{7}{|l|}{$\mathrm{B}$} \\
\hline $11.00-11.99$ & 2 & 2 & $12.00( \pm 0.00)$ & $12.58( \pm 0.47)$ & $12-12$ & $12.25-12.92$ \\
\hline $12.00-12.99$ & 3 & 10 & $12.75( \pm 0.17)$ & $12.63( \pm 0.55)$ & $12.58-12.92$ & $12-13.33$ \\
\hline $13.00-13.99$ & 10 & 12 & $12.99( \pm 0.71)$ & $13.21( \pm 0.48)$ & $12.25-14.58$ & $12.42-13.75$ \\
\hline $14.00-14.99$ & 10 & 12 & $14.64( \pm 0.24)$ & $14.43( \pm 0.47)$ & $14.01-14.92$ & $13.92-15.25$ \\
\hline $15.00-15.99$ & 15 & 6 & $15.47( \pm 0.38)$ & $15.65( \pm 0.82)$ & $14.75-16.08$ & $14.83-16.67$ \\
\hline $16.00-16.99$ & 12 & 16 & $15.82( \pm 0.68)$ & $16.01( \pm 0.58)$ & $14.42-16.92$ & $15.17-17.25$ \\
\hline $17.00-17.99$ & 9 & 11 & $17.5( \pm 0.62)$ & $17.2( \pm 0.49)$ & $15.83-17.92$ & $16.33-17.75$ \\
\hline $18.00-18.99$ & 16 & 5 & $18.2( \pm 0.83)$ & $18.52( \pm 0.32)$ & $16.42-19.08$ & $18-18.83$ \\
\hline
\end{tabular}

and in females at 14 years and 10 months. At the age of 16 in males, numerous interosseous bone bridges are present in the growth plate (Fig. 3b), while the females at about 16 years old show an almost complete fusion of the growth plate. A residual hypointense line usually persists as a lateral incisure in the tubular bones (Fig. 3e).

5. The last grade of skeletal maturation-corresponding to a complete fusion of the epiphysis for the tubular bones and to a complete ossification of the carpal bone-is present in male subjects at the age of 18: before the complete fusion of epipheseal plate, a residual hypointense line usually persists as a lateral incisure in the tubular bones (Fig. 2c). Females show a complete fusion at 17 years old (Fig. 2e).

Our results are quite good in relation to the literature. Dvorak et al. [45] studied the fusion of the left distal radial epiphysis and its correlation with chronological age. The correlation between age and grade of fusion was $r=0.69$. We found a good linear correlation between the sum of the grade of each bone, and the chronological age was observed (in females $R^{2}=0.96$ and in males $R^{2}=0.94$ ). The inter-rater reliability $(r)$ in Dvorak et al. ranged between 0.91 and 0.92 . In our case, inter-rater agreement Pearson $\left(R^{2}\right)$ coefficient was performed, and an excellent linear correlation was found both in male and female groups, respectively, 0.98 and 0.97 .

Schmidt et al. [46] tested Greulich and Pyle's method on hand radiographs of healthy subjects and found that the standard deviations for the age range 13-16 years old varied from 0.3 to 1.7 years. Schmidt et al. [47] tested TW2 and TW3 methods on hand X-rays and in this case the standard deviations for the age range 13-16 years old varied from 0.4 to 1.1 years with TW2 and from 0.4 to 1.2 years with TW3. Tomei's method, in the same age ranges, showed standard deviations between 0.1 and 0.9 years.

Schmidt et al. [47] also tested TW2 and TW3 methods in the legally relevant skeletal age group 14-16 years and found

Table 2 Interobserver variation

\begin{tabular}{|c|c|c|c|c|c|c|}
\hline & \multicolumn{3}{|l|}{ CA-operator A } & \multicolumn{3}{|l|}{ CA-operator B } \\
\hline & $\begin{array}{l}\text { Mean age } \\
\text { disparity (years) }\end{array}$ & $\begin{array}{l}\text { Standard deviation } \\
\text { of disparity (years) }\end{array}$ & $\begin{array}{l}95 \% \text { confidence } \\
\text { interval }\end{array}$ & $\begin{array}{l}\text { Mean age } \\
\text { disparity (years) }\end{array}$ & $\begin{array}{l}\text { Standard deviation } \\
\text { of disparity (years) }\end{array}$ & $\begin{array}{l}95 \% \text { confidence } \\
\text { interval }\end{array}$ \\
\hline Females $(n=74)$ & 0.09 & 0.064 & -0.03 to 0.22 & 0.04 & 0.056 & -0.07 to 0.15 \\
\hline Males $(n=77)$ & 0.14 & 0.6 & 0.005 to 0.3 & 0.03 & 0.59 & -0.10 to 0.16 \\
\hline
\end{tabular}


a

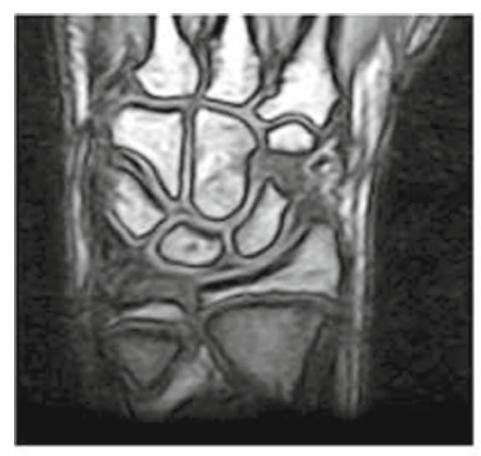

d

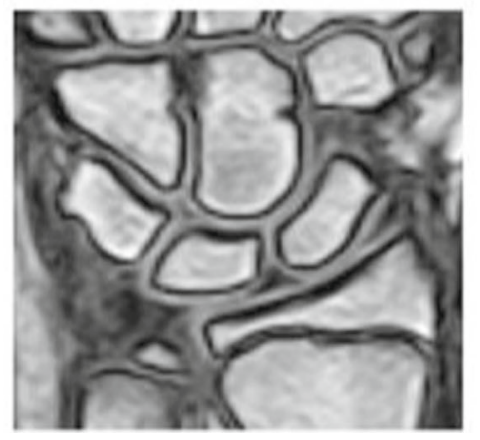

b

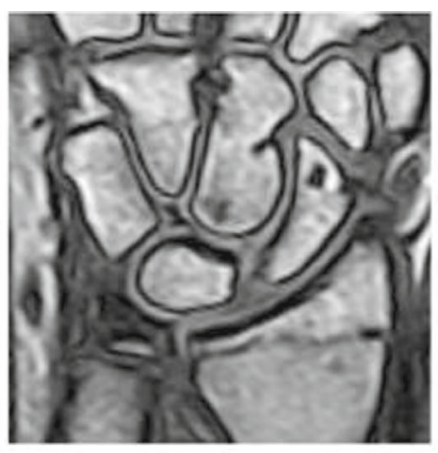

e

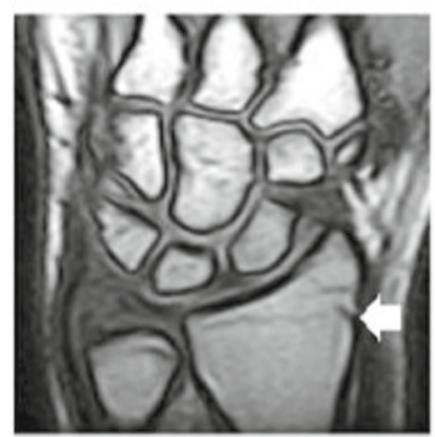

C

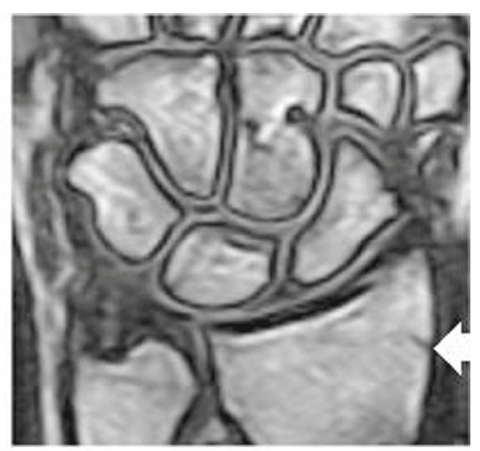

f

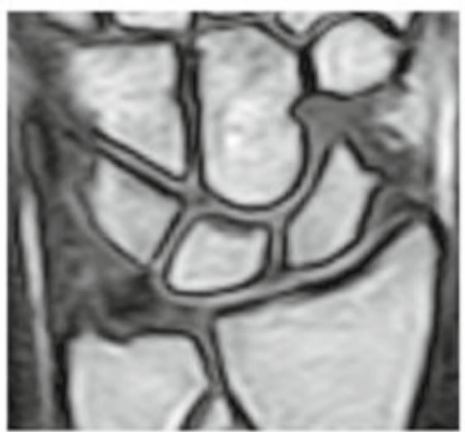

Fig. 3 T1 MRI coronal images of male children of 14, 16, and 18 years old (respectively, figures $\mathbf{a}, \mathbf{b}, \mathbf{c}$ ) compared with females of the same ages (respectively, figures $\mathbf{d}, \mathbf{e}, \mathbf{f}$ ). The males, compared with the females of same age, show a delay in skeletal age maturation, presenting the growth plate open. The females at the age of 16 years old show $\mathbf{e}$ a radial incisure (arrow), while the males present it at the age of 18 years old (c) that there was a risk of serious overestimations for TW2 method (the differences between the skeletal age and the mean value of the chronological age were between -0.1 and +1.4 years). In the same age range, we found differences between -0.8 and +0.2 years. Therefore, Tomei's method seems to provide a reduced risk of overestimation in this age range. At the skeletal age of 18 , in our sample, the differences between the skeletal age and the mean value of the chronological age were between -0.5 and -0.2 years.

Even if our results are good, the current recommendation of a combination of methods (physical, dental, and skeletal examination: hand-wrist and clavicles) should always be taken into account, especially for medico-legal purposes. In fact, none of the existing methods is absolutely precise, as they present a margin of error (over/underestimation) due to two important factors: the first one is the variability of skeletal maturation, which changes among individuals of the same chronological age depending on genetic characteristics and environmental conditions; the second one is the error made by the operator, which depends mostly on his experience.

A reasonable conclusion from the above discussion is that Tomei et al. method [35], even if it is yet infieri, can provide a good accuracy for age determination. In fact, in comparison with X-ray, MRI can be proposed as an instrument for age assessment as it leads to evaluate not only bone segments but also the cartilage changes occurring during the maturation process $[45,48-50]$, due to a good individuation of the ossification nuclei by means of its tissue contrast. Lack of ionizing radiation and relative lack of operator dependence are additional advantages comparing with X-rays, computed tomography and ultrasound. Moreover, the use of the open low-field clinical magnet allows the maximum comfort for the tested person (avoiding claustrophobia and the difficulties for larger people) and minimizes potential biohazards associated with the presence of metal, by placing only the limb of interest in the magnet bore [51]. The limitation of this procedure is the high costs, the possibility of artifacts, the presence of pacemakers and metallic devices, and the limited presence of MRI scanners in the territorial structures where these examination have to be performed.

\section{Conclusions}

MRI does not use ionizing radiation and is fundamentally more accurate than X-ray due to its high contrast resolution. It may assume an important role in forensic age determination. Initial findings show a good correlation between Tomei'S MRI skeletal age and chronological age. 


\section{References}

1. Ritz-Timme S, Cattaneo C, Collins MJ, Waite ER, Schutz HW, Kaatsch HJ et al (2000) Age estimation: the state of the art in relation to the specific demands of forensic practice. Int J Legal Med 113(3): $129-136$

2. UNICEF (2007) Progress for children — a world fit for children statistical review. United Nations Children's Fund, New York

3. Schmeling A, Grundmann C, Fuhrmann A, Kaatsch HJ, Knell B, Ramsthaler F et al (2008) Criteria for age estimation in living individuals. Int J Legal Med 122(6):457-460. doi:10.1007/s00414-0080254-2

4. Separated Children in Europe Programme-Thematic Group on Age Assessment (2011) Review of current laws, policies and practices relating to age assessment in sixteen European Countries. http:// www.separated-children-europe-programme.org/publications/ reports/Age Assessment report review of current policies and practice_in_Europe 2011_pdf.pdf. doi:10.1542/peds.2011-2381

5. Schmeling A, Olze A, Reisinger W, Geserick G (2001) Age estimation of living people undergoing criminal proceedings. Lancet 358(9276):89-90

6. House of Lords, House of Commons and Joint Committee on Human Rights (2007) The treatment of asylum seekers - tenth report of session 2006-07. The Stationery Office Limited, London

7. Council of Europe-Parliamentary Assembly (2011) Unaccompanied children in Europe: issues of arrival, stay and return — doc. 12539. http://assembly.coe.int/ASP/Doc/XrefViewPDF. asp? FileID $=12776 \&$ Language $=$ en

8. Separated Children in Europe Programme - SCEP (2010) Statement of good practice, 4th edn. http://www.refworld.org/docid/ 415450694.html

9. Schmeling A, Olze A, Reisinger W, Geserick G (2004) Forensic age diagnostics of living people undergoing criminal proceedings. Forensic Sci Int 144(2-3):243-245

10. Malina RM, Bouchard C, Bar-Or O, McGraw KA, McGraw C (2004) Growth, maturation, and physical activity. Human Kinetics, Champaign

11. Loder RT, Estle DT, Morrison K, Eggleston D, Fish DN, Greenfield ML et al (1993) Applicability of the Greulich and Pyle skeletal age standards to black and white children of today. Am J Dis Child 147(12):1329-1333

12. Ontell FK, Ivanovic M, Ablin DS, Barlow TW (1996) Bone age in children of diverse ethnicity.AJR. Am J Roentgenol 167(6):13951398

13. Zhang A, Sayre JW, Vachon L, Liu BJ, Huang HK (2009) Racial differences in growth patterns of children assessed on the basis of bone age. Radiology 250(1):228-235. doi:10.1148/radiol. 2493080468

14. Bogin B, Loucky J (1997) Plasticity, political economy, and physical growth status of Guatemala Maya children living in the United States. Am J Phys Anthropol 102(1):17-32

15. Schmeling A, Reisinger W, Loreck D, Vendura K, Markus W, Geserick G (2000) Effects of ethnicity on skeletal maturation: consequences for forensic age estimations. Int J Legal Med 113:253-258

16. Schmeling A, Reisinger W, Geserick G, Olze A (2006) Age estimation of unaccompanied minors. Part I. General considerations. Forensic Sci Int 159(Suppl 1):S61-S64

17. Schmeling A, Grundmann C, Fuhrmann A, Kaatsch HJ, Knell, Ramsthaler F, Reisinger W, Riepert T, Ritz-Timme S, Rösing SW, Rötzscher K, Geserick G, Study Group on Forensic Age Diagnostics of the German Society of Legal Medicine: criteria for age estimation in living individuals. Available at: Http://Agfad.Uni-Muenster.De/ English/Empfehlungen/Empfehlung_Strafverfahren_Eng.Pdf

18. Cameriere R, De Luca S, Biagi R, Cingolani M, Farronato G, Ferrante L (2012) Accuracy of three age estimation methods in children by measurements of developing teeth and carpals and epiphyses of the ulna and radius. J Forensic Sci 57(5):1263-1270. doi:10. $1111 / j .1556-4029.2012 .02120 . x$

19. Greulich WW, Pyle SI (1959) Radiographic atlas of skeletal development of the hand and wrist. Stanford University Press, Stanford

20. Tanner JM, Whitehouse RH, Cameron N, Marshall WA, Healy MJR, Goldstein H (1988) Assessment of skeletal maturity and prediction of adult height (TW2 method). Academic Press Limited, London

21. Kreitner KF, Schweden F, Schild HH, Riepert T, Nafe B (1997) Die computertomographisch bestimmte ausreifung der medialen klavikula epiphyse - eine additive methode zur altersbestimmung im adoleszentenalter und in der dritten lebensdekade? Fortschr Röntgenstr 166:481-486

22. Wittschieber D, Schulz R, Vieth V, Küppers M, Bajanowski T, Ramsthaler F, Püschel K, Pfeiffer H, Schmidt S, Schmeling A (2014) The value of sub-stages and thin slices for the assessment of the medial clavicular epiphysis: a prospective multi-center CT study. Forensic Sci Med Pathol 10(2):163-169

23. Wittschieber D, Schmeling A, Schmidt S, Heindel W, Pfeiffer H, Vieth V (2013) The Risser sign for forensic age estimation in living individuals: a study of 643 pelvic radiographs. Forensic Sci Med Pathol 9(1):36-43

24. Dedouit F, Auriol J, Rousseau H, Rougé D, Crubézy E, Telmon N (2012) Age assessment by magnetic resonance imaging of the knee: a preliminary study. Forensic Sci Int 217(1-3):232.e1-232.e7

25. Krämer JA, Schmidt $S$, Jürgens KU, Lentschig $M$, Schmeling A, Vieth V (2014) Forensic age estimation in living individuals using 3.0 T MRI of the distal femur. Int J Legal Med 128(3):509-514

26. Groell R, Lindbichler F, Riepl T et al (1999) The reliability of bone age determination in Central European children using the Greulich and Pyle method. Br J Radiol 72:461-464

27. Van Rijn RR, Lequin MH, Robben SG et al (2001) Is the Greulich and Pyle atlas still valid for Dutch Caucasian children today? Pediatr Radiol 31:748-752

28. Beunen G, Cameron N (1980) The reproducibility of TW2 skeletal age assessments by a self-taught assessor. Ann Hum Biol 7(2):155162

29. Hauspie RC, Cameron N, Molinari L (2004) Methods in human growth research. Cambridge University Press, Cambridge (UK)

30. Zhang A, Sayre JW, Vachon L, Liu BJ, Huang HK (2009) Racial differences in growth patterns of children assessed on the basis of bone age. Radiology 250(1):228-235

31. Cox LA (1996) Tanner-Whitehouse method of assessing skeletal maturity: problems and common errors. Horm Res 45(Suppl 2):5355

32. Schmidt S, Schiborr M, Pfeiffer H, Schmeling A, Schulz R (2013) Age dependence of epiphyseal ossification of the distal radius in ultrasound diagnostics. Int J Legal Med 127(4):831-838. doi:10. 1007/s00414-013-0871

33. Bilgili Y, Hizel S, Kara SA et al (2003) Accuracy of skeletal age assessment in children from birth to 6 years of age with the ultrasonographic version of the Greulich-Pyle atlas. J Ultrasound Med 22(7):683-690

34. Mentzel HJ, Vilser C, Eulenstein M et al (2005) Assessment of skeletal age at the wrist in children with a new ultrasound device. Pediatr Radiol 35(4):429-433

35. Tomei E, Battisti S, Martino M, Nissman D, Semelka RC (2014) Text-atlas of skeletal age determination: MRI of the hand and wrist in children. Wiley-Blackwell, Hoboken

36. Tomei E, Sartori A, Nissman D, Al Ansari N, Battisti S, Rubini A, Stagnitti A, Martino M, Marini M, Barbato E, Semelka RC (2014) Value of MRI of the hand and the wrist in evaluation of bone age: preliminary results. J Magn Reson Imaging 39(5):1198-1205

37. Cross TM, Smart RC, Thomson JEM (2003) Exposure to diagnostic ionizing radiation in sports medicine: assessing and monitoring the risk. Clin J Sport Med 13(3):164-170 
38. Eikvil L, Kvaal SI, Teigland A, Haugen M, Grøgaard J (2012) Age estimation in youths and young adults. A summary of the needs for methodological research and development. Publication number Samba/52/12. Available at http://publications.nr.no/1355995517/ Age estimation methods-Eikvil.pdf

39. EURATOM (2010) Draft Euratom basic safety standards directive. $\mathrm{http}: / /$ cc.europa.eu/energy/nuclear/radiation protection/doc/art31/ 2010_02_24_draft_euratom basic_safety_standards_directive.pdf

40. United Nations - Committee on the rights of the child (2005) General comment no 6 - treatment of unaccompanied and separated children outside their country of origin. http://www2.ohchr.org/english/ bodies/crc/docs/GC6.pdf

41. Separated Children in Europe Programme-Thematic Group on Age Assessment (2011) Review of current laws, policies and practices relating to age assessment in sixteen European Countries. http:// www.separated-children-europe-programme.org/publications/ reports/Age_Assessment_report_review_of_current_policies_and practice_in_Europe_2011_pdf.pdf

42. IAEA (2011) Radiation protection and safety of radiation sources: international basic safety standards - Interim Edition. Vienna. http:// www.ilo.org/wcmsp5/groups/public/@ed_protect/@protrav/@ safework/documents/publication/wcms_171036.pdf

43. Schmidt S, Nitz I, Ribbecke S, Shultz R, Pfeiffer H, Schmeling A (2013) Skeletal age determination of the hand: a comparison of methods. Int J Legal Med 127(3):691-698. doi:10.1007/s00414-013-0845-4
44. Benson J, Williams J (2008) Age determination in refugee children. Aust Fam Physician 37(10):821-825

45. Dvorak J, George J, Junge A, Hodler J (2007) Age determination by magnetic resonance imaging of the wrist in adolescent male football players. Br J Sports Med 41(1):45-52

46. Schmidt S, Koch B, Schulz R, Reisinger W, Schmeling A (2008) Studies in use of the Greulich-Pyle skeletal age method to assess criminal liability. Legal Med (Tokyo) 10(4):190-195

47. Schmidt S, Nitz I, Schulz R, Schmeling A (2008) Applicability of the skeletal age determination method of Tanner and Whitehouse for forensic age diagnostics. Int J Legal Med 122(4):309-314

48. Dvorak J, George J, Junge A, Hodler J (2007) Application of MRI of the wrist for age determination in international U-17 soccer competitions. Br J Sports Med 41(8):497-500

49. George J, Nagendran J, Azmi K (2012) Comparison study of growth plate fusion using MRI versus plain radiographs as used in age determination for exclusion of overaged football players. Br J Sports Med 46(4):273-278

50. Terada Y, Kono S, Tamada D, Uchiumi T, Kose K, Miyagi R, Yamabe E, Yoshioka H (2013) Skeletal age assessment in children using an open compact MRI system. Magn Reson Med 69(6):16971702

51. Yoshioka H, Schlechtweg PM, Kose K (2009) Magnetic resonance imaging. In: Weissman BNW (ed) Imaging of arthritis and metabolic bone disease. Elsevier, Philadelphia 